\title{
Who Are The Difficult Employees? Psychopathological Attributions Of Their Co-workers
}

\author{
B. Kemelgor, (E-mail: bhkeme01@ louisville.edu), University of Louisville \\ L. Sussman, University of Louisville \\ J. Kline, University of Louisville \\ Jozef Zurada, (E-mail: jmzura01@ louisville.edu), University of Louisville
}

\begin{abstract}
On a given workday, over 700 workers are attacked, 43,800 employees are harassed and 16,400 are threatened (Hynes, 2001). Yet the literature focuses upon environmental causes; none attempt to identify personal characteristics of the uncivil, deviant or maladaptive employee. This study helps fill this void by exploring the personality correlates of uncivil employee behavior. These employees violate mutual norms of respect, negatively affect organizational performance, and are thus the prototypical difficult employee. Utilizing a unique psycho-pathological approach, the DSM-IV (Diagnostic Statistical Manual) was used as the basis for defining and assessing the perceived personality correlates of these employees' behaviors. Results suggest that narcissistic traits are the modal descriptors for the Difficult Employee, regardless of hierarchical role (boss, peer, subordinate). Implications are discussed with suggestions for future research.
\end{abstract}

Keywords: difficult employee; workplace incivility; narcissism; personality disorders

\section{INTRODUCTION}

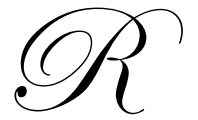

ecent increases in workplace incivility have stimulated a stream of empirical research (Blau \& Andersson, 2005). Workplace incivility is defined as low-intensity deviant behaviors that are rude, discourteous, displaying a lack of respect with ambiguous intent to harm the target, in violation of workplace norms for mutual respect (Andersson \& Pearson, 1999).

The research on incivility, however, has focused upon the target's experience and perception of uncivil behaviors (Blau, et.al., 2005) or how incivility can spiral and potentially escalate into increasingly intense, aggressive workplace behaviors (Andersson, et.al., 1999). Blau and Andersson's (2005) study has identified some factors which might cause instigators to initiate uncivil behavior (italics added). Yet, a careful review of studies addressing workplace incivility (e.g. Cortina \& Magley, 2003; Johnson \& Indvik, 2001; Pearson, Andersson \& Wegner, 2001), and workplace deviant behavior (e.g. Baron \& Neuman, 1996; Folger, Robinson, Dietz, McLean Parks, \& Baron, 1998; O'Leary-Kelly, Griffin, \& Glew, 1996), reveals no attempt to identify personal characteristics of the uncivil, deviant or maladaptive employee. This study seeks to fill this void.

Scholars have cited employee diversity, reengineering, downsizing, budget cuts, increased pressure for productivity, and autocratic work environments as potential external causes of the increase in uncivil and aggressive workplace behavior (Andersson, et.al., 1999; Baron et. al., 1996; Neuman \& Baron, 1997). These causal factors focus on the workplace environment, not the causal factors that could be attributed to an individual employee. Blau et.al. (2005) cite several studies that look more intently upon hypothesized behavioral precipitators such as job insecurity, greater stress including being overworked, and lower general employee satisfaction (italics added). Given that there are many factors within a work environment that could facilitate the occurrence of uncivil or even deviant behavior, the individual must still be viewed as accountable and as a primary source. 
Unfortunately, in designing strategies for coping with and managing workplace incivility before it escalates into deviant behavior, managers and HR professionals confront a semantic quandary. Both the applied and academic literature present a maddening variety of labels and corresponding prescriptions for dealing with these uncivil, "difficult" employees. What are their characteristics? Are they a homogeneous group, or do they fall into discreet categories? And finally, what are the managerial implications if "difficult" employees reflect a modal personality disorder? This study explores these questions thereby clarifying our understanding of the personal characteristics of employees perceived by coworkers as "Difficult"; those defined in the incivility literature as engaging in "Low intensity deviant behaviors" in violation of workplace norms for mutual respect (Andersson, et.al., 1999).

\section{Defining The Difficult Employee}

Descriptors such as "difficult" (Braham, 1989; Grassell, 1989; Morganroth, 1986), "temperamental" (Anderson \& Pulich, 1999), "rebels, criticizers, backstabbers, and busybodies" (Johnson \& Indivik, 2000) suggest that difficult employees run the gamut from troublesome to exasperatingly hellacious.

For our purposes we restrict the term "difficult" to those employees who exhibit workplace incivility by engaging in behaviors that are in violation of workplace norms for mutual respect. Such behavior violate the norms that underpin cooperation and mutual understanding (Dijkstra, van Dierendonck, Evers \& DeDreu, 2005; Pearson, et.al., 2001) and may exacerbate task performance and vice versa (Veiga, 1988). These deviant behaviors often engender emotional distress and oftentimes evoke intense negative reactions from their managers, coworkers, or customers. Viewed in this context, the difficult employee is a disruptive force within the workplace who negatively affects both the working climate and output (Paunonen \& Nicol, 2001).

The foregoing discussion of the "difficult employee" does not assume that their kind exists solely at mid management levels or below. Top-level managers and those in leadership positions may also be equally troublesome and become even greater disruptive forces in the workplace (Deutschman, 2005; Pearson \& Porath, 2005; Lubit 2002; Maccoby, 2000; Kets de Vries, 1993). Thus, regardless of hierarchical level, a difficult employee can impede achievement of organizational objectives, create roadblocks to cooperation and teamwork, elevate stress, and alienate others (Pearson, et.al., 2005; Caborn, 2001; Kets de Vries, 1993; Veiga, 1988).

\section{Challenges For The Manager Or HR Professional}

Once hired, difficult employees quickly become one of the most challenging issues in their workplace, soon gaining a reputation for contrariness, sensitivity to criticism, and argumentativeness. A single difficult employee can taint the atmosphere of even the largest department (Caborn, 2001). Managers, coworkers and subordinates spend inordinate amounts of time discussing how to handle them, how best to speak with them, and how to effectively intervene without becoming embroiled in emotional or legal battles (Pearson, et.al., 2005; Mishra \& Delano, 1988). In some situations, managers may even contemplate how to accomplish the mission around them.

While psychiatrists and psychologists have understandably been cautious in proffering "do-it-yourself" advice for effectively managing deviant personality types, authors in trade and applied management journals have not. At the risk of over generalizing, the thrust of this literature suggests that careful documentation, "tough love", "empathic coaching", "compassionate assertiveness," and "drawing the line in the sand" will lead to the greatest success (Connor, 1999; Lieberman \& Rotarius, 1999; Wisinski, 1992;). However, while the difficult employee's manager prepares for empathic yet assertive coaching, co-workers may "walk on eggshells"; productivity suffers and potential profits are sacrificed. Some types of workplace disruptions can include: threatening behavior (including throwing objects or shaking a fist); oral or written threats, harassment, and verbal abuse (including swearing, insults and indecent language); and behavior that straddles the domains of deviance and aggression (Davis, 1997; Hynes, 2001; Pearson, et. al., 2001). Moreover, failure to effectively manage the difficult employee may result not only in lost profits but threats and injury, and in extreme cases, suicide or homicide (Kline \& Sussman, 2000). A survey of the Fortune 1000 in 2000 indicated that on a given workday, 723 workers are physically attacked, 43,800 are harassed and 16,400 threatening incidents occur (Hynes, 2001). Given that such workplace occurrences, as a 
manifestation of a difficult employee's personality, are a harsh reality in many organizations, there is a greater need to develop our understanding of the underlying psychological characteristics of such employees.

\section{Perception And Personality}

The pleasantness or unpleasantness of an individual is a function of his or her personality and understanding personality enables us to make sense of the complexity of human behavior, sense making which in turn answers both the how and why questions of human behavior. Thus, the personality of an unpleasant or uncivil (difficult) person is a reflection of particular personality traits that are viewed (by others) as maladaptive or pathological, i.e., traits that cause significant problems in the individual's everyday interactions with others. When we observe people, we attempt to develop explanations that help explain why they behave as they do. Following Weiner's (1986) social attribution theory, we tend to infer the causes of another worker's actions as reflecting their internal state. An observer looking at that behavior will attribute causality by references to stable personal dispositions of the actor (Small \& Peterson, 1981). Once we conclude, for example, that person X reflects Y personality traits we are able to comprehend both how that person interacts with others and why that interaction occurs. This social perception allows us to navigate our social environment and infer underlying characteristics and enduring dispositions of the individual (Morris, Menon \& Ames, 2001). As Patsfall and Fiemer (1985) and recently, Nikolaou (2003) noted, personality traits influence perceptions of organizational behavior characteristics. And despite all evidence to the contrary, scholars of workplace deviance have paid relatively little attention to personality (Bernd \& Heinz, 2004).

Workplace deviance and the effects of personality traits merit further research attention and may turn out to be very fruitful (Lee \& Allen, 2002). Thus, behaviors associated with workplace deviance will tend to stand out and likely will be perceived by others. Social perception is guided by conceptions of the kinds of actors acting intentionally (Morris, et.al., 2001). Furthermore, analyses into perception and attribution within organizational psychology have been largely missing (Bernd, et.al., 2004; Lee, et.al., 2002), and very few studies have focused on interactions among coworkers (Struthers, Miller, Boudens, \& Briggs, 2001). This study attempts to address these concerns.

\section{Research Purpose}

The preceding discussion underscores the thesis that problems caused by maladaptive/pathological personality are many and varied (Roberts \& Hogan, 2001) and may appear at all levels of the hierarchy (Yukl, 1998; Morgan, McCall \& Lombardo, 1983). Whether the employee comes to the organization with "emotional baggage" or is someone who develops problems while working there -- perhaps through stress -- the adjustments and reactions made by the employee are manifestations of personality. If the employee was not effectively screened prior to employment, masked his maladaptive personality during a probationary period, or developed a problem personality while on the job, personality related problems will surface and organizational performance will suffer.

Since relatively few researchers have focused on the "dark side" of organizational life (Pearson, et. al., 2001) and personality at work is studied almost completely with reference to performance (Dijkstra, et. al., 2005), the purpose of the present study sought to develop an empirically based profile of the "difficult employee", one grounded on a psychopathological model. To the extent that we demonstrate the descriptive power of the model, important guidelines for dealing with the "uncivil employee" may be developed, guidelines of significant value for both managers and human resource professionals.

Using the Diagnostic Statistical Manual of Mental Disorders $4^{\text {th }}$ ed. (DSM-IV) (American Psychiatric Association, 1994), the ten personality disorders described therein were used as the basis for the study. The DSM-IV is a categorical diagnostic system in which a diagnosis is made only when a specified number of criteria for a particular disorder are met. Within the community of clinical professionals, the DSM-IV is the most comprehensive and widely adopted diagnostic/taxonomic system in use in the United States (Bagby, Marshall, \& Georgiades, 2005). 
These ten personality disorders briefly defined are:

1. Paranoid - a pattern of distrust and suspiciousness such that others' motives are interpreted as malevolent.

2. Schizoid - a pattern of detachment from social relationships and a restricted range of emotional expression.

3. Schizotypal - a pattern of acute discomfort in close relationships, cognitive or perceptual distortions, and eccentricities of behavior.

4. Antisocial - a pattern of disregard for, and violation of, the rights of others.

5. Borderline - a pattern of instability in interpersonal relationships, self-image, and affects, and marked impulsivity.

6. Histrionic - a pattern of excessive emotionality and attention seeking.

7. Narcissistic - a pattern of grandiosity, need for admiration, and lack of empathy.

8. Avoidant - a pattern of social inhibition, feelings of inadequacy, and hypersensitivity to negative evaluation.

9. Dependent - a pattern of submissive and clinging behavior related to an excessive need to be cared for.

10. Obsessive-Compulsive - a pattern of preoccupation with orderliness, perfectionism and control.

Given the exploratory nature of this study, research questions rather than directional hypotheses provide the focus and scope. Insights into understanding and effectively dealing with the difficult employee will emerge in answers to the following three research questions:

Q1: Do difficult employees share common maladaptive personality traits? If so, what are these traits?

Q2: What is the relationship if any, between hierarchical role (supervisor, subordinate, peer) of difficult employees and their underlying personality traits?

Q3: What is the relationship, if any, between age and gender of difficult employees and their underlying personality traits?

\section{METHOD}

A questionnaire was developed based upon diagnostic personality criteria taken from the Diagnostic Statistical Manual of Mental Disorders, 4th Ed. (American Psychiatric Association, 1994). This questionnaire solicited data for developing the psychopathological profile of "Difficult Employee", based upon the perceptions of those who worked with and were affected by the ${ }^{1}$. Using resources from seven different communities, working professionals were asked to complete the instrument .All data were collected over a three-month period, resulting in a total $n$ of 330 .

\section{RESULTS}

Only 312 of the 330 returned questionnaires were used in the data analysis. Eighteen questionnaires were rejected because respondents marked more than 3 traits in one or more of the 4 groups of traits. For the final sample of 312 respondents, 58\% described a difficult employee who was a former coworker; $42 \%$ described a current coworker. Results will be presented in three sections: 1) an analysis of background data, demographic and organizational affiliation; 2) a descriptive analysis of the personality traits and profiles; and 3) statistical tests of relationships among personality profiles and demographic characteristics of the difficult employee.

\section{Analysis Of Demographic Data}

More than half of the respondents (55.4\%) are between the age of 21 and 30, with slightly more males $(51.6 \%)$ than females $(48.4 \%)$. The respondents' estimates of the difficult employee's age reveal that $84.9 \%$ of the difficult employees were estimated as falling within a 21-50 age range, with an apparent even distribution within this range. Among the difficult employees, there are slightly more females (51.6\%) than males (48.4\%). Comparing

\footnotetext{
${ }^{1}$ Information on the development of the questionnaire and the data collection procedures can be obtained by emailing the lead author.
} 
data sets reveals, as a group, the respondents were younger than the difficult employees and contained slightly more males. A plurality (40.1\%) of the difficult employees represented peers of the respondents.

Finally, the majority $(75.1 \%)$ of the respondents and difficult employees were employed in a service type organization. Slightly more than a third (36.7\%) were employed in small companies with less than 100 workers; slightly more than one fourth $(26.3 \%)$ were employed in organizations with more than 1,000 employees.

\section{Analysis Of Trait And Personality Disorder Data}

Table I presents the 10 most frequently selected personality traits and the percentage of respondents who selected them. Taken as a whole, this Table demonstrates the descriptive power of the questionnaire. Ten of the 76 items (13\%) elicited convergent perceptions ranging from $23.7 \%$ to $42.6 \%$ of the sample. The most striking finding of this Table is almost half the sample (42.6\%) selected the trait: "Behavior or attitude is arrogant or haughty". Moreover, half of the traits $(53,68,23,19$, and 37) within this set of most frequently selected traits, represent the narcissistic personality disorder. Traits 26,65 , and 40 represent the borderline, schizotypal, and antisocial personality disorders, respectively. Traits 41 and 60 represent the obsessive-compulsive personality disorder.

Table 1

The 10 most frequently selected personality traits. T_53 stands for trait 53 on the questionnaire

\begin{tabular}{|l|c|c|}
\hline \multicolumn{1}{|c|}{ Trait Description } & Frequency & Percent \\
\hline T_53: Behavior or attitude is arrogant or haughty & 133 & 42.6 \\
\hline T_68: Takes advantage of others to achieve his or her own ends & 127 & 40.7 \\
\hline T_26: Shows emotional instability as evidenced by marked emotional reactions & 119 & 38.1 \\
\hline $\begin{array}{l}\text { T_23: Has a sense of entitlement, i.e., has unreasonable expectations of especially favorable } \\
\text { treatment or automatic compliance with his or her expectations }\end{array}$ & 103 & 33.0 \\
\hline T_19: Has a grandiose sense of self-importance & 102 & 32.7 \\
\hline $\begin{array}{l}\text { T_41: Is preoccupied with details, rules, lists, order, ... to the extent that the major point of the } \\
\text { activity is lost }\end{array}$ & 93 & 29.8 \\
\hline T_65: Lacks close friends or confidants & 90 & 28.8 \\
\hline T_60: Shows rigidity and stubbornness & 88 & 28.2 \\
\hline $\begin{array}{l}\text { T_40: Consistent irresponsibility, as indicated by repeated failure to sustain consistent work } \\
\text { behavior or honor financial obligations }\end{array}$ & 76 & 24.4 \\
\hline T_37: Lacks empathy & & 74 \\
\hline
\end{tabular}

Figure 1 presents the frequencies for the top seven traits selected in response to the question: "The trait most responsible for my negative emotional reaction to this employee was \#..." Two conclusions presented in this Figure parallel the findings in Table I. First, item 19, a narcissistic trait ("Has a grandiose sense of self importance"), was selected by $33 \%$ of all respondents and was selected most frequently as the trait most responsible for the respondent's negative reaction. Secondly, Traits 19, 23, and 53 found in both Figure 1 and Table I, reflect the narcissistic personality disorder. Traits 26 and 28 represent the borderline personality disorder. Traits 40 and 45 represent the antisocial personality disorder.

Because personality assessments cannot be made solely on the basis of a single trait, but rather a constellation of traits within disorders, we analyzed respondents' grouping of traits within each of the ten disorders. Figure 2 depicts the number of respondents (117 of 312) who selected four or more traits for a particular disorder. The results of this analysis are striking: The frequency for the narcissistic personality (70) dominates the chart. Sixty percent $(60 \%)$ or 70 people selected 4 or more traits within the narcissistic disorder to describe their most difficult employee. The next closest grouping of disorders, schizoid, antisocial, and borderline, each constitute a cluster reflecting approximately $3 \%$ of the sample. Moreover, no subject selected 4 or more traits within the paranoid disorder. 
Figure 1

Frequencies for the top seven traits selected to the question " The trait most responsible for my negative emotional reaction to this employee was \#..."

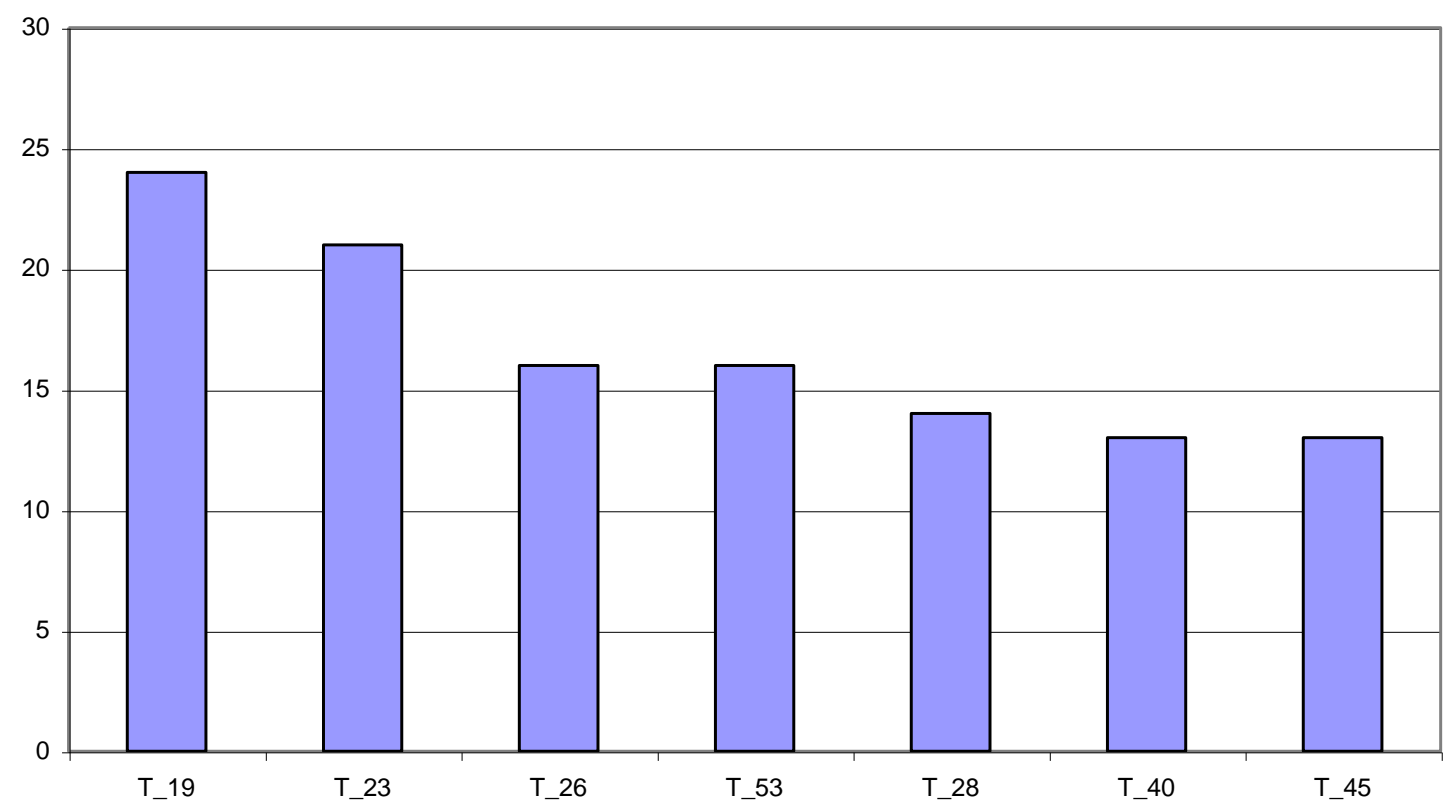

\section{Legend for Figure 1:}

T_19 - Has a grandiose sense of self-importance.

T_23 - Has a sense of entitlement, i.e., has unreasonable expectations of especially favorable treatment.

T_26 - Shows emotional instability as evidenced by marked emotional reaction.

T_53 - Behavior or attitude is arrogant or haughty.

T_28 - Shows inappropriate and intense anger or has difficulty controlling anger.

T_40 - Consistent irresponsibility, repeated failure to meet obligations.

T_45 - Deceitfulness, as indicated by repeated lying or conning others.

Figure 3 displays the total count for the number of times disorder specific traits were selected across the 312 respondents. Again, the narcissistic personality disorder (frequency=703) dominates the 9 remaining disorders. A person with an avoidant personality disorder (frequency $=162$ ) is least likely to create problems in the workplace. 
Figure 2

The number of respondents who selected four or more traits for a particular disorder

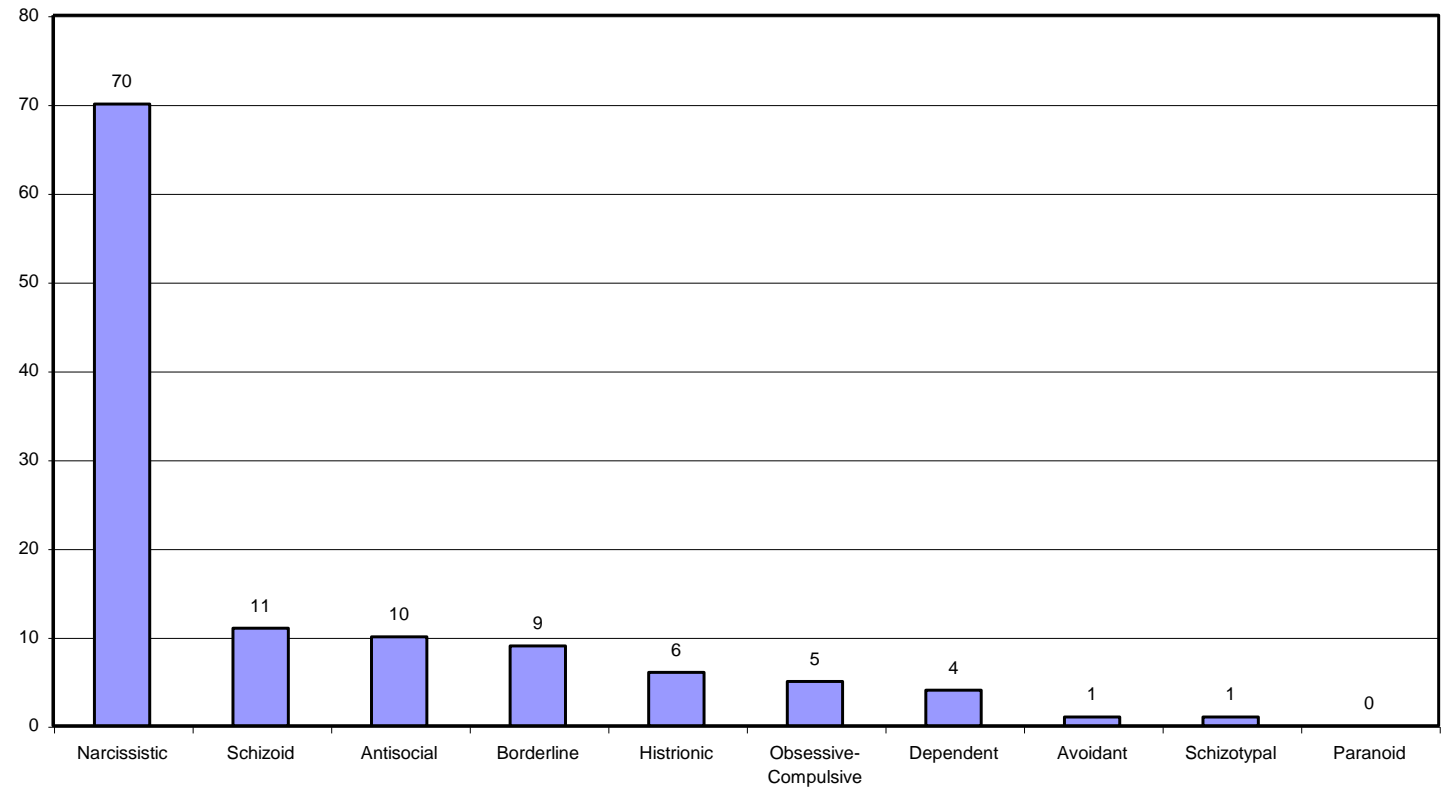

Figure 3

Frequencies of trait specific disorders across all respondents

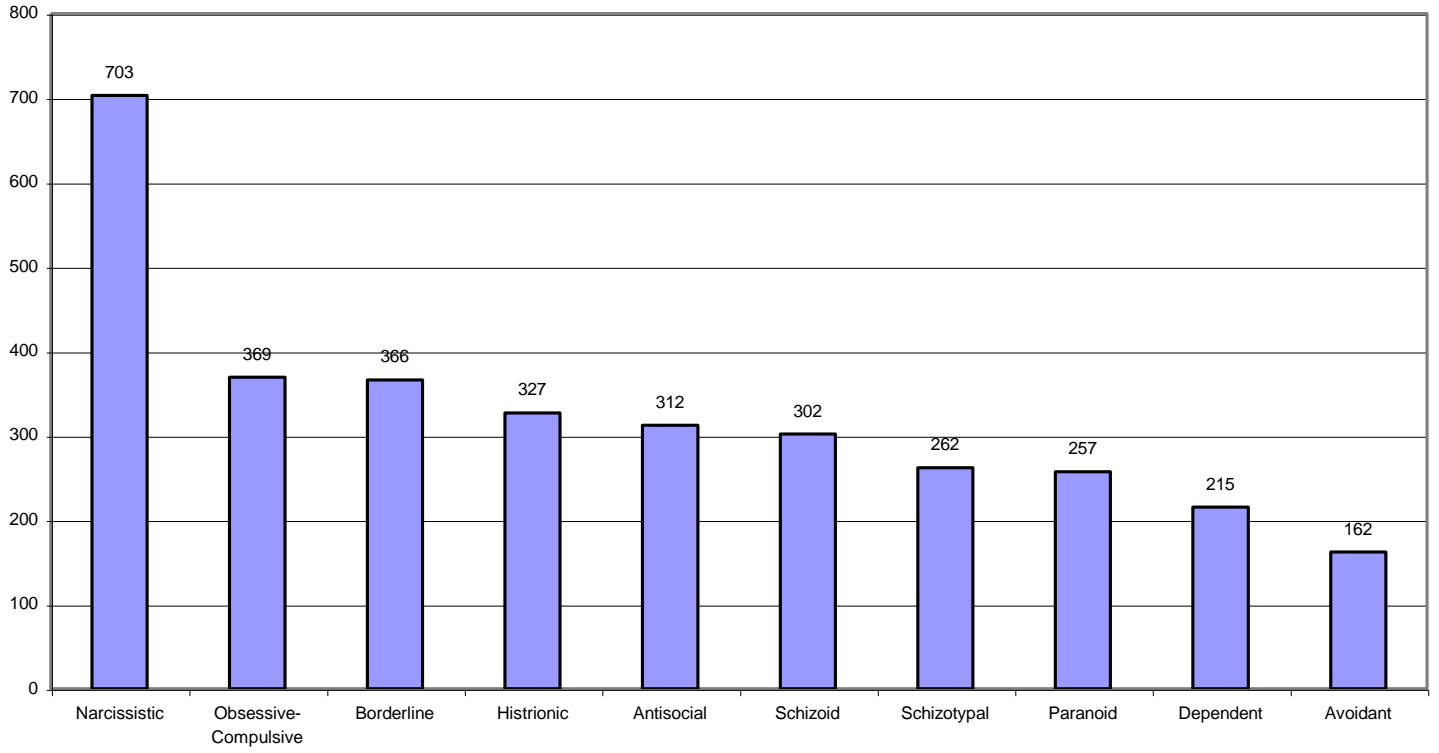




\section{Statistical Tests Of Relationships}

Using the total number of traits selected within each of the 10 disorders, chi square $\left(\chi^{2}\right)$ tests of independence were computed to determine: (1) if the differences among the 10 personality disorders are statistically significant; and (2) if the 10 personality disorders are related to the hierarchical position, age, and gender of the difficult employees.

\section{Differences Among Profiles}

Results of these tests suggest the differences among the population proportions of the 10 personality profiles (Figure 3 ) are statistically significant. The narcissistic and avoidant personality disorders stand out and contribute the most to the $\chi^{2}$ value $\left(\chi^{2}=593.6, \mathrm{df}=9, p<.0001\right)$.

\section{Disorder, Position, And Demographics}

Table 2 displays the observed frequencies of the 10 personality disorders across the 3 hierarchical roles. A test of the independence of the relationship between disorder and roles found a statistically significant relationship $\left(\chi^{2}=42.0, D F=18, p<.001\right)$. Thus, the hypothesis of independence is rejected: the 10 personality disorders are related to the hierarchical role of difficult employees. To find out more about the nature of the association, a cellby-cell examination of the observed and estimated expected frequencies was performed for this Table (Agresti, 2002). The examination reveals that in the supervisor column the narcissistic, paranoid, and avoidant personality disorders stand out and contribute the most to the $\chi^{2}$ value. Unlike subordinates, supervisors are less likely to be avoidant, dependent, borderline, and paranoid and are more likely to be narcissistic, obsessive-compulsive, and antisocial. In addition, when measured across two hierarchical roles: supervisor vs. peer and subordinate (combined) the data strongly suggests the10 personality disorders are dependent on the hierarchical role of difficult employees $\left(\chi^{2}=34.2, D F=9, \mathrm{p}<.0001\right)$. A cell-by-cell comparison of the observed and estimated frequencies confirms the above findings.

Table 2

Two-way table: personality profile $\mathbf{x}$ position of a difficult employee

\begin{tabular}{|c|c|c|c|}
\hline \multirow{2}{*}{ PersonalityDisorder } & \multicolumn{3}{|c|}{ Position of the difficult employee } \\
\cline { 2 - 4 } & Supervisor & Subordinate & Peer \\
\hline Paranoid & 45 & 100 & 109 \\
\hline Schizoid & 84 & 95 & 119 \\
\hline Schizotypal & 61 & 81 & 114 \\
\hline Antisocial & 86 & 109 & 153 \\
\hline Borderline & 79 & 133 & 278 \\
\hline Histrionic & 69 & 115 & 66 \\
\hline Narcissistic & 211 & 212 & 87 \\
\hline Avoidant & 29 & 66 & 152 \\
\hline Dependent & 44 & 83 & 111 \\
\hline
\end{tabular}

To further probe the relationship between personality disorder and hierarchical role, we converted frequency counts for each of the 10 disorders into ranks. The top 3 (1-3) and bottom 3 (8-10) ranks for each of the hierarchical positions are presented in Table 3. As the data in this Table suggest, narcissism is the top ranked disorder across all three roles. However, whereas both the supervisor and peer are perceived as possessing obsessive-compulsive personality qualities, the supervisor stands out among the three roles as possessing antisocial qualities. The major conclusion in comparing the bottom three ranks across the roles is that avoidance and dependent traits are commonly shared in the bottom ranks across the three hierarchical roles. Thus, when rank ordered, avoidant and dependent personality disorders appear to be less problematic than the other eight personality disorders, regardless of the hierarchical role of the difficult employee. 
Table 3

Top 3 (1-3) and bottom 3 (8-10) ranks of personality disorders for each of the hierarchical roles

\begin{tabular}{|c|c|c|c|}
\hline \multirow{2}{*}{ Personality Disorder } & \multicolumn{3}{|c|}{ Position of the difficult employee } \\
\cline { 2 - 4 } & Supervisor & Subordinate & Peer \\
\hline Paranoid & 8 & & 8 \\
\hline Schizoid & & 9 & \\
\hline Schizotypal & & 2 & 2 \\
\hline Antisocial & 3 & 3 & 1 \\
\hline Borderline & & 1 & 10 \\
\hline Histrionic & & 10 & 9 \\
\hline Narcissistic & 1 & 8 & 3 \\
\hline Avoidant & 10 & & \\
\hline Dependent & 9 & & \\
\hline Obsessive-Compulsive & 2 & & \\
\hline
\end{tabular}

Because of the low frequencies in the bottom and top of the age ranges, the six age categories in the survey were reduced to four age ranges for data analyses. Table 4 displays the relative frequencies of the 10 personality disorders across the four age groups of the difficult employees. A test of the relationship between profile and age found a statistically significant relationship at $\alpha=0.05\left(\chi^{2}=43.3, D F=27, p=0.02\right)$. Thus, the hypothesis of independence is rejected at $\alpha=0.05$, and in fact the data in Table IV suggest that 10 personality profiles depend on the four age groups of difficult employees. (Note: this hypothesis of independence cannot be rejected at $\alpha=0.01$.)

Examination of the relative and estimated frequencies in this Table reveals that the obsessive-compulsive, histrionic, dependent, borderline, and paranoid personality disorders stand out for at least two age groups and contribute the most to the $\chi^{2}$ value.

To further examine the 10 personality profiles and the four age groups, we ran the $\chi^{2}$ tests to compare all combinations of the four age groups, two age groups at a time. We only found statistically significant relationships at $\alpha=0.05$ between the [<31] age group and each of the three remaining groups. Thus, personality disorders among difficult employees do vary with age. For example, the difficult employees in the [<31] age group tend to be less obsessive-compulsive than their counterparts in the 31 and older age groups. This youngest group of difficult employees also appears to be more dependent and borderline than their counterparts from the older age groups. Also, the difficult employees in the [<31] age group appear to be more histrionic than their counterparts in the oldest age group [>50]. Furthermore, the difficult employees in the oldest group appear to be more paranoid than their counterparts in the 41-50 group.

Table 4

Two-way table: personality profile $x$ age of a difficult employee

\begin{tabular}{|c|c|c|c|c|}
\hline \multirow{2}{*}{ Personality Disorder } & \multicolumn{5}{|c|}{ Age Groups of Difficult Employees } \\
\cline { 2 - 5 } & $\mathbf{3 1}$ & $\mathbf{3 1 - 4 0}$ & $\mathbf{4 1 - 5 0}$ & $\mathbf{5 0}$ \\
\hline Paranoid & 72 & 75 & 65 & 42 \\
\hline Schizoid & 79 & 89 & 90 & 45 \\
\hline Schizotypal & 75 & 74 & 77 & 35 \\
\hline Antisocial & 97 & 89 & 86 & 37 \\
\hline Borderline & 126 & 106 & 96 & 37 \\
\hline Histrionic & 113 & 93 & 207 & 29 \\
\hline Narcissistic & 189 & 218 & 45 & 24 \\
\hline Avoidant & 51 & 41 & 63 & 22 \\
\hline Dependent & 76 & 52 & 118 & \\
\hline Obsessive-Compulsive & 77 & 116 & 58 \\
\hline
\end{tabular}


To further probe the relationships between personality profiles and age groups, we converted relative frequency counts for each of the 10 profiles into ranks. The top three (1-3) and bottom three (8-10) ranks for each of the four age groups are presented in Table 5. As the data in this Table suggest, narcissistic is again the number one ranked profile across all four age groups. Furthermore, the data in this Table reveal that obsessive-compulsive and borderline disorders constitute the next two top ranks and they are shared across three age groups. The major conclusion in comparing the bottom three ranks across the four age groups is that avoidant and dependent personality traits are commonly shared in the bottom ranks across four and three age groups, respectively. Moreover, paranoid and schizotypal disorders are shared across two age groups. Thus, when rank ordered, avoidant, dependent, paranoid, and schizotypal personality disorders appear to be less problematic in the workplace than the other six personality disorders. A more careful examination of the ranks in Table 5 confirms some of the previously described findings that: (1) difficult employees in the youngest age group [<31] do not appear to be as obsessivecompulsive as their counterparts in the three remaining groups; and (2) difficult employees in the youngest group $[<31]$ are more histrionic than their counterparts in the oldest group [ $>50]$.

Table 5

Top three (1-3) and bottom three (8-10) ranks of personality disorders for each of the four age groups

\begin{tabular}{|c|c|c|c|c|}
\hline \multirow[t]{2}{*}{ Personality Disorder } & \multicolumn{4}{|c|}{ Age Groups of Difficult Employees } \\
\hline & $<31$ & $31-40$ & $41-50$ & $>50$ \\
\hline Paranoid & 9 & & 8 & \\
\hline Schizoid & & & & 3 \\
\hline Schizotypal & 8 & 8 & & \\
\hline \multicolumn{5}{|l|}{ Antisocial } \\
\hline Borderline & 2 & 3 & 3 & \\
\hline Histrionic & 3 & & & 8 \\
\hline Narcissistic & 1 & 1 & 1 & 1 \\
\hline Avoidant & 10 & 10 & 10 & 9 \\
\hline Dependent & & 9 & 9 & 10 \\
\hline Obsessive-Compulsive & & 2 & 2 & 2 \\
\hline
\end{tabular}

An examination of the 10 personality disorders across the gender of the difficult employees was conducted. Although the data suggests that women appear to be more histrionic and less antisocial than men, this finding is not statistically significant. $\left(\chi^{2}=14.6, D F=9, p=.10\right)$. Thus, overall the data suggest that the 10 personality disorders tend to be independent of the gender of difficult employees.

\section{DISCUSSION}

The rationale for this study was based on a simple, yet provocative question: do difficult employees, those who exhibit workplace incivility, share a common set of personality traits and do these traits reflect pathological qualities? Based upon operationally defining personality disorders using DSM-IV criteria, the answer to both parts of this question is yes. Moreover, the personality disorders appear to vary across hierarchical role, and across age groups.

Three fourths of our survey respondents (78\%) agreed the pathological personality traits they selected provided an "excellent description" of their most difficult (uncivil) employee. Furthermore, respondents agreed that such employees evoke in them strongly negative emotional reactions. In many cases, their emotional reactions were of sufficient severity to affect their work performance (72 percent).

This study reflects a significant departure from other treatments of workplace deviance or incivility in that we focused upon individual causality and not the work context that has trademarked other studies. The workplace will not cause an individual to reciprocate with a behavior inconsistent with an individual's personality tendencies, yet studies have not addressed this issue (Bernd \& Schuler, 2004; Colbert, Mount, Harter, Wick, \& Barrick, 2004). 
Borrowing from research on the focus effect (Paul \& Eisner, 2006), where comparative judgment is based upon a focus (referent) of comparison, we discover that such comparison has been found to be more reliable in difference judgments (Paul, et .al., 2006). Therefore, asking respondents to consider someone within their workplace who has exhibited workplace incivility that has been troublesome, forced them to consider individuals who were behaviorally different from themselves and others. Thus, differences in behavior are attributed to the actor. To effectively assess this we designed our study to avoid biases of quick closure and cognitive style. Regarding the latter, it should be noted that specific intentionality of individuals is more likely to come to mind for perceivers in one culture than another, even when cognitively available in both cultures (Morris, et. al., 2001). For example, a substantial body of evidence suggests that, compared with Americans or Western Europeans, Chinese are less inclined to attribute social behavior of individuals to internal dispositions such as personality and more inclined to attend to social institutions, roles and groups (Lehman, Chiu \& Schaller, 2004; Morris, et. al., 2001). Evidence suggests that Chinese, for example, show a reduced bias toward attributing a person's action to dispositions also shows that Americans, given the same stimulus information, attribute the intention of a person to the person's mental state (Lehman, et. al., 2004; Morris, et. al., 2001). Morris, et. al. (2001) go on to say there is a mixed track record of empirical evidence to support cultural differences in judgment, but they persist because they are the only game in town. Since we forced respondents to make choices about a focal individual's behavior based upon highly differentiated statements regarding behavioral traits, and removed context from the instrument, we believe many of the cultural bias may have been ameliorated. Given the instrument asked for knowledge about a significant other under conditions where the respondent likely had little attention to spare, it was also important to avoid response under quick cognitive closure. Therefore, by designing a thorough assessment instrument, one requiring thought prior to responding, we hopefully avoided this bias, and likely grounded results in a more intensive evaluative process.

Within our sample, traits of narcissistic personality disorder were the modal descriptors. This finding holds for both the total number of narcissistic traits selected by the entire group of respondents, as well as the number of narcissistic traits selected by individual respondents. Moreover, narcissism was selected as the modal personality type in each of the three hierarchical roles (peer, subordinate, boss), and in each of the four age groups. Although specific clusters of personality disorder traits varied across age groups and across hierarchical roles, narcissism emerged as the dominant disorder. Statistically significant gender differences did not emerge across any of the ten personality disorders.

The overrepresentation does not mean narcissistic workers are necessarily far more abundant in the workplace than workers with other disorders. A more likely interpretation for our findings is narcissistic traits simply may evoke more intense negative emotional reactions from others than do other personality traits. Further, it does not matter whether the person exhibits many or few of the traits. The narcissist becomes the 'red flag' within the workplace - the person exhibiting the most obvious incivility. This finding is not surprising because, as Fox and Spector (1999) demonstrated, narcissistic individuals are most prone to negative emotional arousal and anger.

The psychiatric literature highlights the problems narcissists create in the workplace. Individuals with narcissistic personality disorder "...may expect great dedication from others and may overwork them without regard for the impact on their lives" (American Psychiatric Association, 1994, p. 659). This feature may be particularly problematic when an individual with strong narcissistic features is in a position of authority (Deutschman, 2005; Lubit, 2002; Maccoby, 2000).

In his trait-profile of narcissistic personality disorder, Stone (1994, p. 259) lists the following descriptors: "affected, arriviste, arrogant, boastful, conceited, contemptuous, dandyish, haughty, hypercritical, know-it-all, mannered, name-dropping, patronizing, pompous, pretentious, prima donna, sanctimonious, self-righteous, smug, snobbish, stilted, and vain." Robins and Paulhus (2001) cite several studies that add "arrogant, critical, defensive, denigrating others, hostile and interpersonally insensitive" to this list. With traits such as Stone, and Robins and Paulhus describe, is it any surprise that narcissistic individuals, exhibiting workplace incivility, evoke intense negative responses in their workplace associates? 
Our study provides empirical support for both the DSM-IV's interpretation and the two trait specific lists noted above. Narcissistic traits were four of the top seven most frequently selected traits. Moreover, when asked to select the single trait which best explained the reason for their negative reactions to the difficult employee, $42.6 \%$ of our sample selected "Behavior or attitude is arrogant or haughty," a criterion of narcissistic personality disorder.

While the borderline trait of emotional instability was the third most common trait ascribed to the most difficult employee, borderline personality disorder traits as a whole fell far short of the number of traits seen for narcissistic personality disorder. There are several possible explanations for this finding.

In the clinical experience of one of the authors, borderline individuals are not only considerably warmer than narcissists despite their propensity for rapid mood shifts, but they are also more likely to seek relationships. These individuals can nurture others, with the expectation that "the nurtured friend or colleague will be there for them as well" (American Psychiatric Association, 1994, p. 651).

In contrast, narcissistic individuals tend to lack empathy, that ability to resonate with and understand the feelings and needs of others (Judge, LePine \& Rich, 2006). Compared to most people, high narcissists have been found to exhibit a high dominance/ low nurturance interpersonal orientation (Robins, et. al., 2001). Narcissists' lack of empathy and understanding as well as their demanding sense of entitlement may make them more abrasive than individuals with borderline traits. This aligns itself with the workplace incivility definition including rude, discourteous and lack of respectful behaviors.

Moreover, compared to narcissists, employees with borderline personality disorder may have greater difficulty maintaining employment. In other words, workers with borderline personality disorders may simply not be around long enough to develop the mantle, "Difficult Employee." In contrast, individuals with severe narcissistic personality disorder may be more likely to retain their employment status (often much to the disappointment of those who work with them). Their diminished frequency of depressions and relative scarcity of suicide attempts along with their intense desire for others to perceive them as superior appear to sustain them in the workplace.

The answers to the research question posed earlier provide a dramatic picture of the psychopathological profile of difficult employees. These employees may appear at all levels of the hierarchy, may be young or old, are equally likely to be male or female, and are more likely than not to reflect narcissistic traits. The findings of this study also underscore the importance of an emerging body of literature addressing the narcissistic employee (Ket de Vries, 1993; Lubit, 2002; Maccoby, 2000).

Our findings also suggest that for the manager or human resource professional, faced with the challenge of dealing with narcissistic type behaviors, there are a couple of guidelines that might ameliorate the situation. First, as Fox et. al. (1999) suggest, narcissists react negatively to work or job constraints. Perhaps couching these limitations in the workplace as guidelines and helping the narcissist see the rationale for the constraint as leading to a better quality workplace (recall, the narcissist see themselves as excellent performers) will minimize counterproductive workplace behavior. Second, we would caution against placing suggested narcissistic individuals in positions where they are subject to a lot of feedback about their work. Again, narcissists are low in agreeableness and high in egocentricity. Minimizing situations where feedback would be viewed as an attack upon the self concept of the narcissist is likely to make the workplace more comfortable for everyone involved.

\section{Implications For Future Research}

As an exploratory study, we recognize much more remains to be done. We have demonstrated the ability to profile the difficult employee - something called for but not yet documented in the literature. Further study needs to be longitudinally conducted using full time employed professionals who would permit study of the evolution of the relationship between the difficult employee and the respondent. Since we did not control for how long the respondent had worked with the target person, perhaps length of working relationship would be an intervening variable. Additionally, a comparative study across specific industries might reveal the extent of incidents as a function of the work environment (e.g. hierarchical vs. flat, high stress vs. routine). For example, Somech and 
Drach-Zahavy (2004) report on the results of several studies that found bureaucratic organizations create environments of employee alienation. We believe this is exactly the type of work climate [narcissistic] difficult employees would find most threatening.

To the extent corporate culture rewards haughtiness and arrogance, the narcissist may be problematic but also a model for others to emulate. Case studies of the apparent hubris and smugness in the executive suite immediately prior to ENRON's collapse add credence to notion that narcissistic traits may not only be acceptable in certain organizations but implicitly and/or explicitly reinforced (Deutschman, 2005; Zellner \& Forest, 2001). Future research should not only explore the underlying reasons why narcissism is a dominant personality among difficult employees but also the role corporate culture may play in enabling and/or suppressing that behavior. It is believed a competitive culture, where the organization values competition or a bureaucratically structured organization may precipitate incidences of workplace incivility. Thus, corporate cultures may reinforce and enable the uncivil behavior that becomes problematic for managers and employees within that culture.

Since much of the evidence in the literature suggests supervisors intervene only if the behavior of the difficult employee adversely affects performance (e.g. Hopkins, 1997) or manifests itself in aggression (Pearson, et al., 2001), we believe that our findings suggest a broader, more inclusive interpretation of "performance". In our study, $72 \%$ of the respondents claimed the actions of the difficult employee significantly affected their (the respondents) work behavior, yet organizational realities suggest that such effect largely goes on unabated. It's only when the difficult employee's behavior affects his or her work performance, that the manager is likely to become involved (Hopkins, 1997). Further study needs to be conducted that investigates the extent to which the behavior of difficult employees negatively affects the organizational climate resulting in higher turnover or greater absenteeism of witnesses or target employees, and lost customers.

Our research findings may also reveal the relationship between high narcissism and self-enhancement within the workplace. Narcissism and self-enhancement have been demonstrated to be highly correlated, (Robins, et.al. , 2001). What may be viewed by the individual and organization as appropriate behavior for fast trackers may, in fact, be viewed by coworkers as a complete lack of respect (Deutschman, 2005). Early success within a work context coupled with accolades from above may serve as catalysts for self-assured performers to engage in behaviors reflecting heightened narcissism. As a result, rather than composed self-esteem, some individuals may resort to self-enhancement and self-promotion to the dismay of their co-workers. To use an analogy, the Muhammad Ali of the corporation shouting "I am the greatest", may be so inspired by their own arrogance that it facilitates their success. However, for every successful narcissist, there likely are numerous "failed" narcissists, "wallowing in obscurity and complaining about how their exceptional talents remain unrecognized by their supervisors and coworkers" (Robins, et. al., 2001; 212). Given the results of our research, the rapid rise-and-fall of the worker with narcissistic personality disorder is particularly likely. Future research should explore this possibility.

Hopkins (1997) cites several studies indicating that when an employee's deviant behavior negatively affects productivity, a supervisor is apt to take notice but if that behavior is of a more personal nature the supervisor often delays action or fails to act at all. If performance is best defined as being a function of employees' workplace behaviors (Dunlop \& Lee, 2004) and both occupational citizenship behavior (OCB) as well as workplace deviant behavior (WDB) (significantly correlated constructs) influence workplace performance (Dunlop, et. al., 2004), to what extent is the negative behavior a function of narcissistic personality? It is herein maintained that it is not enough to identify poor OCB or inhibiting WDB, but rather understanding the causality would offer managers and leaders greater facility in dealing with such behavior. Realizing that the difficult employee is more apt to be narcissistic than anything else, their behavior will most likely engender exasperation and frustration rather than constructive action. Research needs to be conducted that evaluates the effectiveness of various interventions, thus moving concerns from the popular press to knowledge-based transactions. 


\section{REFERENCES}

1. $\quad$ Agresti, A. (2002). Categorical Data Analysis. Somerset, NJ: Wiley.

2. Anderson, P., \& Pulich, M. (1999). Managing the temperamental employee, Health Care Supervisor, 17, 28-36.

3. Andersson, L.M. \& Pearson, C.M. (1999). Tit for tat? The spiraling effect of incivility in the workplace. Academy of Management Review, 24, 452-471.

4. American Psychiatric Association (1994). Diagnostic and Statistical Manual of Mental Disorders , $4^{\text {th }}$ ed. Washington D.C.: Author.

5. Bagby, R., Marshall, M. \& Georgiades, S. (2005) Dimensional personality traits and the prediction of DSM-IV personality disorder symptom counts in a nonclinical sample. Journal of Personality Disorders, 19, 53-67.

6. Baron, R. \& Neuman, J. (1996). Workplace violence and workplace aggression: Evidence on their relative frequency and potential causes. Aggressive Behavior, 22, 161-173.

7. Blau, G. \& Andersson, L. (2005). Testing a measure of instigated workplace incivility. Journal of Occupational and Organizational Psychology, 78, 595-614.

8. $\quad$ Braham, J. (1989). Difficult employees. Industry Week, 238 (12), 30-34.

9. Caborn, A. (2001). Sorting the bad apples. Director, 54(11), 23-24.

10. Colbert, A., Mount, M., Harter, J., Witt, L. \& Barrick, M. (2004). Interactive effects of personality and perceptions of the work situation on workplace deviance. Journal of Applied Psychology, 89(4), 599-609.

11. Connor, J. (1999).The paranoid personality at work. HR Magazine, 44(3), 120-126.

12. Cortina, L. \& Magley, V. (2003). Raising voice, risking retaliation: Events following interpersonal mistreatment in the workplace. Journal of Occupational Health Psychology, 8, 247-265.

13. Davis, D. (1997). Threats pending, fuses burning: Managing workplace violence. Palo Alto CA: DaviesBlack.

14. Deutschman, A. (2005). Is your boss a psychopath? Fast Company, July, 44-51.

15. Dijkstra, M., van Dierendonck, D., Evers, A., \& De Dreu, C. (2005). Conflict and well-being at work: the moderating role of personality. Journal of Managerial Psychology, 20, 87-101.

16. Dunlop, P. \& Lee, K. (2004). Workplace deviance, organizational citizenship behavior and business unit performance: The bad apples do spoil the whole barrel. Journal of Organizational Behavior, 25, 67-80.

17. Folger, R., Robinson, S., Dietz, J., McLean Parks, J. \& Baron, R. (1998). When colleagues become violent: Employee threats and assaults as a function of societal violence and organizational injustice. Proceedings of the Academy of Management National Meeting, A1-A7.

18. Grassell, M. (1989). How to supervise difficult employees. Supervision, 50(7), 3-5.

19. Hopkins, K. (1997). Supervisor intervention with troubled workers. Human Relations, 50, 1215-1239.

20. Hynes, D. (2001). Preventing Workplace Violence: Towards an Aggression-Free Workplace. Ottawa: The Conference Board of Canada.

21. Johansen, M., Karterud, S., Pedersen, G., Gude, T., \& Falkum, E., (2004). An investigation of the prototype validity of the borderline DSM-IV construct. Acta Psychiatrica Scandinavica, 109, 289-298.

22. Johnson, P. \& Indvik, J. (2000). Rebels, criticizers, backstabbers, and busybodies: Anger and aggression at work. Public Personnel Management, 29, 165-174.

23. Johnson, P. \& Indvik, J. (2001). Rudeness at work: Impulse over restraint. Public Personnel Management, $30,457-465$.

24. Judge, T., LePine, J. \& Rich, B., (2006) Loving yourself abundantly: Relationship of the narcissistic personality to self- and other perceptions of workplace deviance, leadership and task performance. Journal of Applied Psychology, 91(4), 762-776.

25. Kets de Vries, M. (1993). Leaders, fools, and imposters. San Francisco CA: Jossey-Bass.

26. Kline, J. \& Sussman L. (2000). Major depression in the workplace. Academy of Management Executive, 14 (3), 103-113.

27. Lee, K. \& Allen, N. (2002). Organizational citizenship behavior and workplace deviance: The role of affect and cognitions. Journal of Applied Psychology, 87(1),131-142.

28. Lehman, D., Chiu, C. \& Schaller, M. (2004). Psychology and culture. Annual Review of Psychology, 55, 689-714. 
29. Lieberman, A. \& Rotarius, T. (1999). Behavioral contract management: A prescription for employee and patient compliance. The Health Care Manager, 18(2), 1-10.

30. Lubit, R.(2002). The long term impact of destructively narcissistic managers. Academy of Management Executive, 16 (1), 127-138.

31. Maccoby, M. (2000). Narcissistic leaders: the incredible pros, the inevitable cons. Harvard Business Review, 78(1), 68-77.

32. Marcus, B. \& Schuler, H. (2004). Antecedents of counterproductive behavior at work: A general perspective. Journal of Applied Psychology, 89(4), 647-660.

33. Morgan, M., McCall, W. Jr., \& Lombardo, M. (1983). Off the track: Why and how successful executives get derailed. Bottomline, 7(9), 24-30.

34. Morgenroth, W. M. (1986). Handling the difficult employee. Business and Economic Review, 32, 12-16.

35. Morris, M., Menon, T. \& Ames, D. (2001). Culturally conferred concepts of agency: A key to social perception of persons, groups and other actors. Personality and Social Psychology Review, 5(2), 169-182.

36. Neuman, J. \& Baron, R. (1997). Aggression in the Workplace. In Giacalone, R. \& Greenberg, J. (Eds.) Antisocial Behavior in Organizations. Thousand Oaks, CA: Sage.

37. Nikolaou, I. (2003). Fitting the person to the organization: examining the personality-job performance relationship from a new perspective. Journal of Managerial Psychology, 18, 639-648.

38. O’Leary-Kelly, A., Griffin, R. \& Glew, D. (1996). Organization-motivated aggression: A research framework. Academy of Management Review, 21, 225-254.

39. Pahl, S. \& Eiser, J. (2006). The focus effect and self-posivity in ratings of self-other similarity and difference. British Journal of Social Psychology, 45, 107-116.

40. Patsfall, M. \& Fiemer, N. (1985). The role of person-environment fit in job performance and satisfaction., In Bernardin, H. \& Bownas, D. (Eds.) Personality Assessment in Organizations. New York: Prager.

41. Paunonen S. \& Nicol, A. (2001). The personality hierarchy and the prediction of work behaviors. In Roberts, B. \& Hogan, R. (Eds) Personality Psychology in the Workplace. Washington, D.C.: American Psychological Association.

42. Pearson, C., Andersson, L. \& Wegner, J. (2001). When workers flout convention: A study of workplace incivility. Human Relations, 54, 1387-1419.

43. Pearson, C. \& Porath, C. (2005). On the nature, consequences and remedies of workplace incivility: No time for Nice? think again. Academy of Management Executive, 19(1), 7- 18.

44. Roberts, B. \& Hogan, R. (2001). Introduction: Personality and Industrial Organizational Psychology. In Roberts, B. \& Hogan, R. (Eds) Personality Psychology in the Workplace. Washington, D.C.: American Psychological Association.

45. Robins, R. \& Paulhus, D. (2001). The character of self-enhancers, In Roberts, B. \& Hogan R. (Eds) Personality Psychology in the Workplace. Washington D.C.: American Psychological Association.

46. Small, K. \& Peterson, J. (1981). The divergent perceptions of actors and observers. The Journal of Social Psychology, 113, 123-132.

47. Somech, A \& Drach-Zahavy, A. (2004). Exploring organizational citizenship behaviour from an organizational perspective: The relationship between organizational learning and organizational citizenship behaviour. Journal of Occupational and Organizational Psychology, 77, 281-298.

48. Stone, M. (1994). Abnormalities of personality: Within and beyond the realm of treatment. New York: Norton.

49. Struthers, C., Miller, D., Boudens, C., \& Briggs, G. (2001). Effects of causal attributions on coworker interactions: A social motivation perspective. Basic and Applied Social Psychology, 23(3), 169-181.

50. Veiga, J. (1988). Face your problem subordinates now! The Academy of Management Executive, 2, 145153 .

51. Weiner, B. (1986). An attributional theory of motivation and emotion. New York: Springer - Verlag.

52. Wisinski, J. (1992). A logical approach to a difficult employee. HR Focus, 69(l), 9-10.

53. Yukl, G. (1998). Leadership in Organizations, $4^{\text {th }}$ ed. Englewood Cliffs, N.J.: Prentice Hall.

54. Zellner, W. \& Forest, A. (2001). The Fall of Enron. Business Week, 17 Dec., 30. 


\section{NOTES}

